The following resources related to this article are available online at www.sciencemag.org (this information is current as of August 21, 2009 ):

Updated information and services, including high-resolution figures, can be found in the online version of this article at:

http://www.sciencemag.org/cgi/content/full/309/5733/401

Supporting Online Material can be found at:

http://www.sciencemag.org/cgi/content/full/309/5733/401/DC1

A list of selected additional articles on the Science Web sites related to this article can be found at:

http://www.sciencemag.org/cgi/content/full/309/5733/401\#related-content

This article has been cited by 37 article(s) on the ISI Web of Science.

This article has been cited by 5 articles hosted by HighWire Press; see:

http://www.sciencemag.org/cgi/content/full/309/5733/401\#otherarticles

This article appears in the following subject collections:

Medicine, Diseases

http://www.sciencemag.org/cgi/collection/medicine

Information about obtaining reprints of this article or about obtaining permission to reproduce this article in whole or in part can be found at:

http://www.sciencemag.org/about/permissions.dtl 


\title{
Health Innovation Networks to Help Developing Countries Address Neglected Diseases
}

\author{
Carlos M. Morel, ${ }^{1 *}$ Tara Acharya, $^{2}$ Denis Broun, ${ }^{3}$ Ajit Dangi, ${ }^{4}$ Christopher Elias, ${ }^{5}$ N. K. Ganguly, ${ }^{6}$ Charles A. Gardner, ${ }^{7}$ \\ R. K. Gupta, ${ }^{8}$ Jane Haycock, ${ }^{9}$ Anthony D. Heher, ${ }^{10}$ Peter J. Hotez, ${ }^{11}$ Hannah E. Kettler, ${ }^{12}$ Gerald T. Keusch, ${ }^{13}$ \\ Anatole F. Krattiger, ${ }^{14}$ Fernando T. Kreutz, ${ }^{15}$ Sanjaya Lall, ${ }^{16}$ Keun Lee, ${ }^{17}$ Richard Mahoney, ${ }^{14}$ \\ Adolfo Martinez-Palomo, ${ }^{18}$ R. A. Mashelkar, ${ }^{19}$ Stephen A. Matlin, ${ }^{20}$ Mandi Mzimba, ${ }^{21}$ \\ Joachim Oehler, ${ }^{22}$ Robert G. Ridley, ${ }^{23}$ Pramilla Senanayake, ${ }^{24}$ Peter Singer, ${ }^{25}$ Mikyung Yun $^{26}$
}

\begin{abstract}
Gross inequities in disease burden between developed and developing countries are now the subject of intense global attention. Public and private donors have marshaled resources and created organizational structures to accelerate the development of new health products and to procure and distribute drugs and vaccines for the poor. Despite these encouraging efforts directed primarily from and funded by industrialized countries, sufficiency and sustainability remain enormous challenges because of the sheer magnitude of the problem. Here we highlight a complementary and increasingly important means to improve health equity: the growing ability of some developing countries to undertake health innovation.
\end{abstract}

Improving the health of the poorest people in the developing world depends on the development and deployment of many varieties of health innovations, including new drugs, vaccines, devices, and diagnostics, as well as new techniques in process engineering and manufacturing, management approaches, software, and policies in health systems and services. In developed countries, philanthropic and government donors have created and invested more than $\$ 1$ billion in global product development partnerships (PDPs) to develop and help to ensure access to new drugs, vaccines, and diagnostics for diseases of the poor (1). These PDPs have made major progress in a relatively short time period (2) but continue to face many challenges.

All developing countries can undertake health innovation to varying degrees. Some developing countries, however, are more scientifically advanced than others and are starting to reap benefits from decades of investments in education, health research infrastructure, and manufacturing capacity. We refer to these as innovative developing countries (IDCs) $(3,4)$.

It is a challenge to get complete data on health research spending. According to the most recent available data, public spending on health research by developing countries totaled at least $\$ 2$ billion (5). This number does not include China, for which data were not available. That investment, which has already led to important innovations, is projected to continue to grow $(3,5-7)$. Furthermore, lower labor and other costs have the potential to magnify the impact of this investment. To put it in a different perspective, just $1 / 10$ th of these IDC public health research re-

${ }^{14}$ BioDesign Institute, Arizona State University, Tempe, AZ 85287-4501, USA. ${ }^{15}$ FK Biotecnologia, Avenida Bento Gonçalves 9500, Building 43431, Campus do Vale, Federal University of Rio Grande do Sul, Porto Alegre, RS 91501-970, Brazil. ${ }^{16}$ Oxford University, Queen Elizabeth House, 21 Saint Giles, Oxford OX1 3LA, UK ${ }^{17}$ Department of Economics, Seoul National University, Shillim-dong, Seoul, 151-742, Korea. ${ }^{18}$ Ministry of Health, Periférico Sur 4118, Edifico Zafiro I, primero piso, Col. Jardine, DF 01900, Mexico. ${ }^{19}$ Council for Scientific and Industrial Research, Anusandhan Bhawan, 2 Rafi Marg, New Delhi 110 001, India. ${ }^{20}$ Global Forum for Health Research, 1-5 Route de Morillons, Post Office Box 2100, Geneva 2, CH-1211, Switzerland. ${ }^{21}$ Department of Science and Technology, South African Embassy, 26 Rue de la Loi, Brussels 1040, Belgium. ${ }^{22}$ The Concept Foundation, 111 Paholyothin Road, Thailand Science Park, Klongluang, Pathumthani 12120, Thailand. ${ }^{23}$ Tropical Disease Research Program, World Health Organization, Geneva $27 \mathrm{GE}, \mathrm{CH}-1211$ Switzerland. ${ }^{24} \mathrm{Clobal}$ Forum for Health Research, 79 Hyde Park Corner, Colombo 2, Sri Lanka. ${ }^{25}$ University of Toronto, 88 College Street, Toronto, ON M5G-1L4, Canada. ${ }^{26}$ Korea Institute for International Economic Policy, Seocho-gu, Yeomgokdong, 300-4 Seoul, 137-747 Korea.

*To whom correspondence should be addressed. E-mail: morel@fiocruz.br sources amounts to more than all that was spent in 2004 by the above-mentioned PDPs engaged in the development of drugs, vaccines, and diagnostics for diseases of the poor $(8,9)$.

Patents and well-cited publications indicate the productivity of research investments, and in this light, IDCs have made major progress. The number of U.S. patents per capita is a common proxy used to measure the relative innovation efficiency of countries, but we believe that this computation underestimates the innovative capacity of developing countries, because it fails to detect the productivity of highly capable centers of excellence within countries with large populations. Adjusting for both relative economic status and population (U.S. patents per gross domestic product per capita) (10), the top 25 most productive countries in the world include India, China, Brazil, South Africa, Thailand, Argentina, Malaysia, Mexico, and Indonesia (10). For Brazil, China, India, and South Africa, the number of highly cited academic papers rose nearly twofold from 1993-1997 to 1997-2001 (11), whereas the number of U.S. patents has increased 10-fold (12).

Academic research, publications, and patents do not help the poor (or anyone else) unless they are turned into tangible products or improved practices and policies. Detailed analyses and comparisons of countries' performance in turning ideas into innovations are limited (13), but there are case examples that imply growing capabilities. IDCs have a publication intensity that is much higher than the global average in health biotechnology fields that are relevant to the health needs of their own populations (14). As far as specific products now on the market, the list includes the following: (i) the first effective meningitis $\mathrm{B}$ vaccine, developed at the $\mathrm{Cu}$ ban Finlay Institute and recently licensed to GlaxoSmithKline (15); (ii) new innovative processes for engineering local versions of the recombinant hepatitis B vaccine in Cuba, Korea, and India (16); and (iii) the antimalarial drug arteether (a semi-synthetic artemisinin derivative), developed at India's Central Drug Research Institute and transferred to Themis Chemicals for commercial development, now sold under the brand name E-mal in 48 countries (17). In terms of innovative health programs, Brazil's human immunodeficiency virus/acquired immunodeficiency syndrome (HIV/AIDS) program stands 
out, because it has combined the local manufacturing of antiretrovirals and government financing to provide free access to all who need the drugs (18). A number of companies from IDCs are working on new products in collaboration with the global PDPs, including FIOCRUZ/Bio-Manguinhos and Butantan Institute of Brazil with the Human Hookworm Vaccine Initiative (19), Ranbaxy and Bharat Biotech in India with the Malaria Vaccine Initiative, and the Serum Institute of India with the Meningitis Vaccine Initiative.

Developing countries also play an increasingly important role in manufacturing health products to meet global health needs. China is the world's leading producer of penicillin. The Serum Institute of India is the world's leading manufacturer of diphtheria-pertussis-tetanus vaccine. Over $60 \%$ of the United Nations Children's Fund's vaccine requirements for the Expanded Programme on Immunization are met by Brazil, Cuba, India, and Indonesia $(20,21)$. In dollar terms, $67 \%$ of India's drug exports and $74 \%$ of Brazil's drug exports go to other developing countries, whereas $63 \%$ of Uganda's drug imports and $54 \%$ of Tanzania's drug imports come from other developing countries (22). By volume, India is now the fourth largest producer of pharmaceuticals in the world (23).

Some observers have emphasized the need for developing countries to "build their own capacity to develop drugs, particularly in the case of neglected diseases ... for which multinational pharmaceutical companies may have little interest in investing because the market is unlikely to provide adequate returns" (24). Yet there may be tensions between national health priorities and the desire for economic development (25). Al- though the Commission on Macroeconomics and Health has emphasized the direct link between health and economic development (26), others underscore the need to consciously align innovation policies and health priorities in a way that is consistent with the legitimate goals of wealth and job creation (27).

These perspectives help to highlight specific questions that require further study. For example: Under what conditions might a market that seems unattractive to a developed-country company be attractive to its developing-country counterpart? Under what circumstances might companies in the individual IDCs build a business based on national health needs, as opposed to global diseases with blockbuster profit potential? Are there opportunities for IDCs to help least-developed countries, either through the manufacture and export of low-cost products or through technical assistance and capacity building (28)? Is it in their economic interest to do so? In considering such questions, we raise the following points, each of which is based on observations that require further study

1) Public-sector infrastructure. Unlike in wealthier countries, most health research (and some manufacturing) in developing countries is funded by and conducted in the public sector and therefore may be driven more by public health goals $(5,29,30)$.

2) Low-cost production. C. K. Prahalad points out (31) that some manufacturers in developing countries pursue a business model in which they specialize in high-volume, low-margin production, which leads to low-cost products, and they often explicitly develop products with the goal of distributing them to the poor in

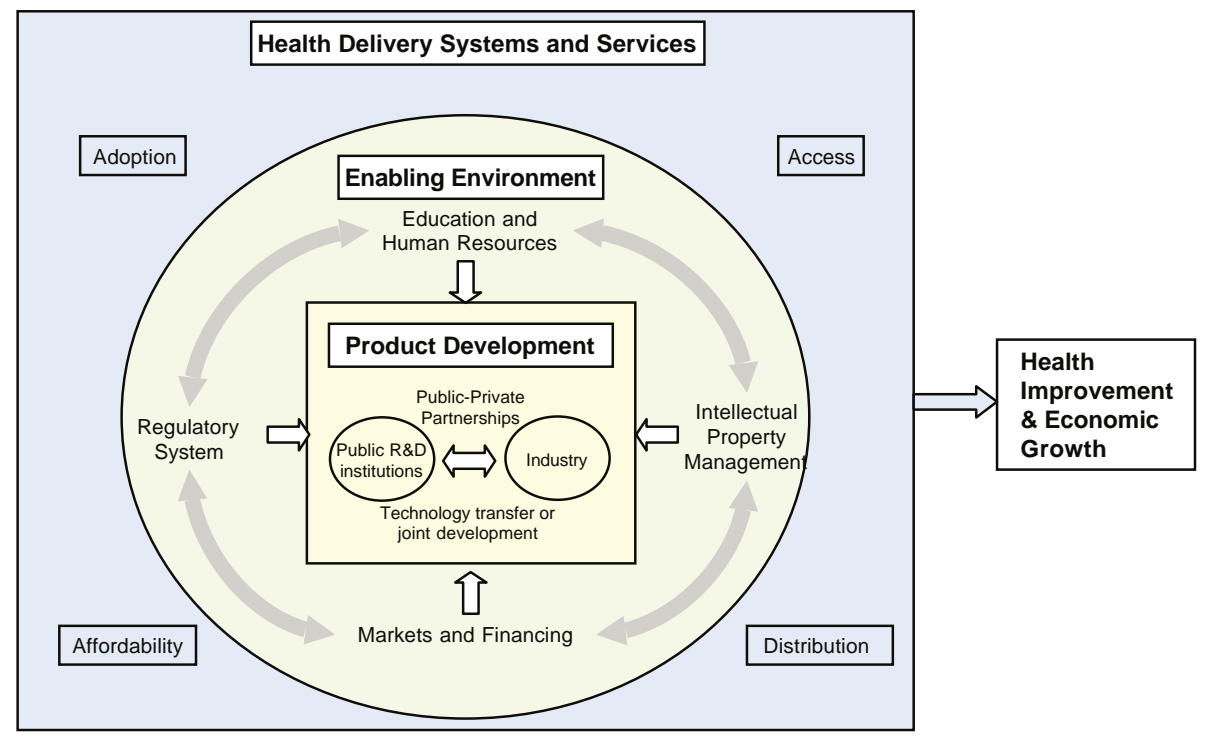

Fig. 1. Health innovation systems have multiple components, operating in both the public and private sectors, including the following: education, research, financing, manufacturing, technology management practices, intellectual property rules, regulatory rules, and domestic and export markets (including public procurement). The system refers not only to these components but also to the technical, commercial, legal, social, and financial interactions; the interlinkages among components; and the policies and practices that guide them. The function (or dysfunction) of and dynamic linkages among these components contribute to the production and delivery of health products and services to people —or lack thereof. developing-country markets. Manufacturing cost advantages (32) mean that products produced in developing countries may be more affordable, an important factor in access to medicines.

3) Acceptability and social conscience. Those closest to the needs of the poor are the affected communities, scientists, policymakers, and institutions in developing countries. This proximity may motivate innovation for treating diseases of the poor. IDC products may also be more acceptable to governments and consumers in developing countries.

A recent study of innovation systems in health biotechnology in developing countries found that policies and practices affecting local public-private partnerships (PPPs), sustained government support for research, the retention and expansion of the scientific corps, the availability of venture capital, and manufacturing and regulatory approvals are particularly important factors in innovation to meet national health needs (6). Given that currently most of the infrastructure for health research in developing countries resides in the public sector $(5,29,30)$, we believe that innovation through partnering of local public and private research organizations deserves particular attention. National innovation policies to encourage such partnerships, and capacity building in the management of intellectual property, among other competencies, can help make such partnerships more effective.

In 2002, the U.K. Commission on Intellectual Property Rights suggested the need for "a network of the public-private partnerships in developing countries, taking advantage of the concentration of research resources in public sector institutions but also the opportunity to build research capacity in the private sector" (33). Given the large and growing investments by IDCs in health research, we strongly advocate a network for health innovation in developing countries that promotes policy research, local innovation, Southto-South learning, and information sharing (Fig. 1).

Several networks have already formed, focusing on individual diseases, technologies, or components of health innovation systems. In April 1994, FIOCRUZ and the Special Programme for Research and Training in Tropical Diseases (TDR) organized in Rio de Janeiro the first Parasite Genome Network Planning Meeting (Fig. 2). The Developing Country Vaccine Manufacturers' Network, established in November 2000, includes both state-owned and private producers in Brazil, Cuba, China, India, Indonesia, and Mexico that are prequalified by the World Health Organization (WHO) for sale to United Nations (UN) agencies. The South-South Initiative (SSI) in tropical diseases research, a TDR initiative begun in 1991, is designed to facilitate sharing of resources among research groups in Latin America, Asia, and Africa in order to increase competitiveness and optimize scientific opportunities. The SSI currently in its full operation is managed by a coordinating committee representing African, Asian, and Latin American 


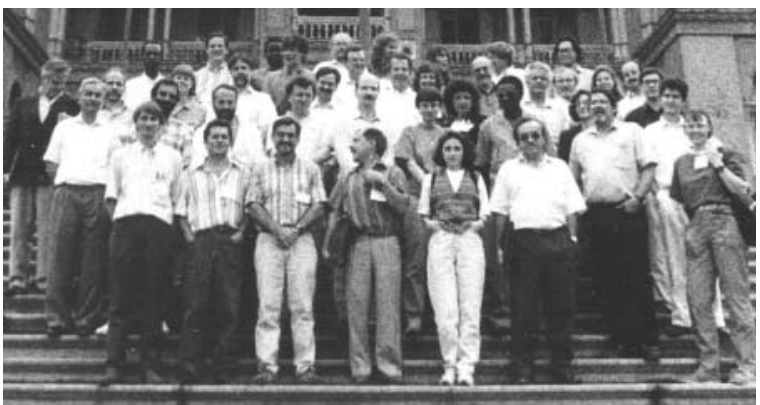

Fig. 2. Group photograph of the participants of the FIOCRUZ-TDR Parasite Genome Network Planning Meeting, held in Rio de Janeiro, Brazil, on 14 and 15 April 1994. This international meeting, attended by 40 scientists and 5 representatives from WHO, selected the three parasite strains whose genome sequences are published in this issue of Science by the Tritryp project.

investigators (34). The India-Brazil-South Africa Dialogue Forum, established in June 2003, includes a focus on intellectual property and access to medicine, traditional medicine, and R\&D on vaccines and pharmaceutical products to address national health priorities. The Technological Network on HIV/AIDS, which was announced in Bangkok during the July 2004 International AIDS Conference, includes Brazil, China, Cuba, Nigeria, Russia, Thailand, and Ukraine (with perhaps India and South Africa joining in the near future). The Network supports research and South-South technology transfer to develop and manufacture antiretroviral drugs and new drug formulations, male and female condoms, microbicides, and HIV vaccines. Finally, the WHO Developing Countries' Vaccine Regulators Network, created in September 2004, involves Brazil, China, Cuba, India, Indonesia, Russia, South Africa, South Korea, and Thailand.

Broader networks could expand linkages to other like-minded organizations (35). We believe that more frequent robust exchanges of know-how among an expanding universe of public- and private-sector players would accelerate innovation and expedite the translation of knowledge about diseases of the poor while also reflecting national sensitivities, changing contexts, and the concomitant desire for economic growth. This goal will also require bringing together two communities whose communication has been, in our opinion, far from optimal. A growing body of scholarly economic studies has examined innovation systems in developing countries $(6,20,36-38)$. This work tends to equate well-being with wealth creation, and it is built largely on case studies from the electronics, information technology, engineering, and other nonhealth manufacturing industries. At the same time, global health professionals concerned with the discovery, development, and introduction of new health technologies - who are, in fact, working to address challenges that are directly related to the components of health innovation systems have not systematically applied concepts and methodologies from the field of innovation systems in their work. A network approach could help maximize substantial existing investments in health research made by IDCs and also complement global efforts to address health disparities and achieve the Millennium Development Goals.

We have sought to highlight two points: (i) A rapidly evolving phenomenon: IDCs are increasingly capable of health innovation to address their national health priorities and to help meet the needs of less advanced developing countries. (ii) A knowledge gap: Innovation systems theory has rarely been applied to global health problems, whereas the global health community has rarely focused on innovation systems (39). We believe that new insights may arise at the intersection of these two cultures and research communities (40).

\section{References and Notes}

1. R. Widdus, K. White, Combating Diseases Associated with Poverty, Financing Strategies for Product Development and the Potential Role of Public-Private Partnerships, (www.who.int/entity/intellectualproperty/ topics/ppp/en/CombatingDiseases-Abridged.pdf).

2. M. Moran, submissions to the Commission on Intellectual Property Rights, Innovation and Public Health of the WHO: New Approaches to Funding Drug $R \& D$ for Neglected Diseases (www.who.int/entity/ intellectualproperty/submissions/Mary.Moran.pdf) and Fast Track Options as a Fundraising Mechanism to Support R\&D into Neglected Diseases (www.who.int/entity/ intellectualproperty/submissions/Mary.Moran2.pdf).

3. C. Morel et al., Innovation Strategy Today 1, 1 (2005); available at www.biodevelopments.org/innovation/ index.htm.

4. These concepts spring from the meeting "Accelerating Product Development and Ensuring Product Access for Diseases of Poverty: The Role of Public-Private Partnerships in Developing Countries" held in Bellagio, Italy, on 10 to 13 May 2004.

5. Global Forum for Health Research, Monitoring Financial Flows for Health Research, Vol. 2 (Global Forum for Health Research, Geneva, 2004), pp. 14-15.

6. Nat. Biotechnol. Suppl. 22 (125), (2004).

7. UN Millennium Project and UN Development Group, Interim Report of Task Force 10 on Science, Technology and Innovation (1 February 2004); available at www. unmillenniumproject.org.

8. This is an estimate by C. A. Gardner based on annual reports and grant applications from the product development PPPs and personal communications with individual PPP chief executive officers.

9. These PPPs include the International AIDS Vaccine Initiative, the International Partnership for Microbicides, the Medicines for Malaria Venture, the Malaria Vaccine Initiative, the Global Alliance for Tuberculosis (TB) Drug Development, and Aeras Global TB Vaccine Foundation.

10. Materials and methods are available as supporting material on Science Online.

11. D. A. King, Nature 430, 311 (2004).

12. For more information, see www.uspto.gov.

13. Knowledge for Better Health, Strengthening Health Systems, The Mexico Statement on Health Research, from the Ministerial Summit on Health Research Mexico City, 16 to 20 November 2004.

14. H. Thorsteinsdóttir, personal communication.

15. "YM Bio Springs a Cuban Surprise," Financial Times, 14 June 2002.

16. See www.who.int/csr/disease/hepatitis/ whocdscsrlyo20022/en/index4.html.

17. R. A. Mashelkar, V. Tripathi, unpublished data.

18. G. C. Levi, M. A. Vitoria, J. Acquir. Immune Defic. Syndr. Hum. Retrovirol. 16, 2373 (2002).
19. P. J. Hotez, J. Bethony, M. E. Bottazzi, S. Brooker, P. Buss, PLoS Med. 2, e67 (2005)

20. C. Grace, The Effect of Changing Intellectual Property on Pharmaceutical Industry Prospects in India and China: Considerations for Access to Medicine (Issues Paper, Health Systems Resource Centre, Department for International Development, United Kingdom, June 2004).

21. According to the Developing Country Vaccine Manufacturers' Network, the number is $64 \%$, excluding oral polio vaccine.

22. H. E. Bale, Commission on Macroeconomics and Health 2001. CMH Working Paper Series Paper No. WG 4:3 (WHO, Geneva, 2001)

23. See www.indiaoppi.com/keystat.htm.

24. House of Commons, The Use of Science in UK International Development Policy (Thirteenth Report of Session 2003 to 2004, October 2004, London).

25. H. Kettler, R. Modi, Bull. World Health Organ. 79, 742 (2001).

26. WHO Commission on Macroeconomics and Health, Macroeconomics and Health: Investing in Health for Economic Development. Report of the Commission on Macroeconomics and Health (WHO, Geneva, 2001).

27. J. C. Pereira, V. T. Baltar, D. L. de Mello, Rev. Saude Publica 38, 1 (2004)

28. In 2002, the Brazilian Ministry of Health created an International Cooperation Programme (ICP) for HIV and AIDS Prevention and Control Activities for Developing Countries "to provide funds for the establishment of ten pilot projects to the annual value of U.S. $\$ 100,000$ each [for] technical assistance and antiretroviral drug supply" (41). Brazil has provided support and antiretroviral drugs to several African and Latin American countries, and both Brazil and Thailand have pledged to assist several African countries to develop antiretroviral manufacturing capacity. Brazil is also the largest producer of yellow fever vaccine in the world.

29. R. Saha et al., IP Strategy Today 9, 23 (2004).

30. The data in (42) support the observation that the public sector accounts for $40 \%$ of health R\&D infrastructure in developed countries but $60 \%$ in developing countries. These data refer to R\&D in general and are not specific to health.

31. C. K. Prahalad, The Fortune at the Bottom of the Pyramid: Eradicating Poverty Through Profits (Wharton School Publishing, Philadelphia, PA, 2004).

32. For example, the Organization of Pharmaceutical Producers of India and Monitor Company Group estimate that basic drug production costs in India are at least $50 \%$ less than in the United States, and in some cases the manufacturer's selling price in India is below production costs of the same product in the United States (43).

33. Commission on Intellectual Property Rights, "Integrating Intellectual Property Rights and Development Policy" (Commission on Intellectual Property Rights, London, 2002).

34. See www.ssi-tdr.net.

35. Examples of such organizations are the Global Forum for Health Research; the UN University Institute for New Technology; the Danish Research Unit for Industrial Dynamics; the Science and Technology Policy Research Unit of Sussex University; the Program for Appropriate Technology in Health; the Global Network for the Economics of Learning, Innovation, and Competence Building Systems; the World Bank Millennium Science Initiative; and a proposed Research Agency Collaborative on Health.

36. C. Dahlman, R. R. Nelson, in Social Capability and Long Term Economic Growth, B. Koo, D. Perkins, Eds. (MacMillan Press, London, 1995), pp. 82-122.

37. C. Edquist, Systems of Innovation for Development, background paper for United Nations Industrial Development Organization World Industrial Development Report 2001 (Vienna, 2001).

38. C. Juma et al., Int. J. Technol. Manage. 22, nos. 7/8 (2001).

39. The global health community, however, has recently embraced the application of systems theory to national health systems.

40. These issues were discussed in April 2005 during a meeting at the Rockefeller Foundation's Bellagio Conference Center, which brought together leading experts from these two fields to recommend a plan of action.

41. Ministry of Health of Brazil, Scaling Up an International Response to AIDS-The Brazilian Initiative (White Paper, National Program on Sexually Transmitted Diseases and AIDS), availiable at www.aids.gov.br. 
42. World Development Report (World Bank, Washington DC, 2005), chap. 3.

43. Organization of Pharmaceutical Producers of India and Monitor Company Group, in Outsourcing Opportunities in Indian Pharmaceutical Industry (Mumbai, India, 2004); available at www.indiaoppi.com/puboutsourcing2003. htm., pp. 24-25.
44. The authors are grateful to all who contributed to this paper and to The Rockefeller Foundation for financial support. The views expressed in this paper are those of the authors in their individual capacities and do not necessarily reflect those of their respective institutions. We dedicate this work to Professor Sanjaya Lall, co-author, Friend and colleague to us all, who passed away on 18 June 2005 .
Supporting Online Material

www.sciencemag.org/cgi/content/full/309/5733/401/ DC1

Materials and Methods

Fig. S1

10.1126/science. 1115538

R E S E A R C H AR T I C LE

\title{
Comparative Genomics of Trypanosomatid Parasitic Protozoa
}

\begin{abstract}
Najib M. El-Sayed, ${ }^{1,2 *} \dagger$ Peter J. Myler, ${ }^{3,4,5 * \dagger}{ }^{3}$ Gaëlle Blandin, ${ }^{1}$ Matthew Berriman, ${ }^{6}$ Jonathan Crabtree, ${ }^{1}$ Gautam Aggarwal, ${ }^{3}$ Elisabet Caler, ${ }^{1}$ Hubert Renauld, ${ }^{6}$ Elizabeth A. Worthey, ${ }^{3}$ Christiane Hertz-Fowler, ${ }^{6}$ Elodie Ghedin, ${ }^{1,2}$ Christopher Peacock, ${ }^{6}$ Daniella C. Bartholomeu, ${ }^{1}$ Brian J. Haas, ${ }^{1}$ Anh-Nhi Tran, ${ }^{7}$ Jennifer R. Wortman, ${ }^{1}$ U. Cecilia M. Alsmark, ${ }^{8}$ Samuel Angiuoli, ${ }^{1}$ Atashi Anupama, ${ }^{3}$ Jonathan Badger, ${ }^{1}$ Frederic Bringaud, ${ }^{9}$ Eithon Cadag, ${ }^{3}$ Jane M. Carlton, ${ }^{1}$ Gustavo C. Cerqueira, ${ }^{1,10}$ Todd Creasy, ${ }^{1}$ Arthur L. Delcher, ${ }^{1}$ Appolinaire Djikeng, ${ }^{1}$ T. Martin Embley, ${ }^{8}$ Christopher Hauser, ${ }^{1}$ Alasdair C. Ivens, ${ }^{6}$ Sarah K. Kummerfeld, ${ }^{11}$ Jose B. Pereira-Leal, ${ }^{11}$ Daniel Nilsson, ${ }^{7}$ Jeremy Peterson, ${ }^{1}$ Steven L. Salzberg, ${ }^{1}$ Joshua Shallom, ${ }^{1}$ Joana C. Silva, ${ }^{1}$

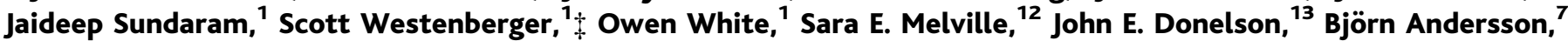
Kenneth D. Stuart, ${ }^{3,4}$ Neil Hall $^{6} \dagger \S$
\end{abstract}

\begin{abstract}
A comparison of gene content and genome architecture of Trypanosoma brucei, Trypanosoma cruzi, and Leishmania major, three related pathogens with different life cycles and disease pathology, revealed a conserved core proteome of about 6200 genes in large syntenic polycistronic gene clusters. Many species-specific genes, especially large surface antigen families, occur at nonsyntenic chromosome-internal and subtelomeric regions. Retroelements, structural RNAs, and gene family expansion are often associated with syntenic discontinuities that-along with gene divergence, acquisition and loss, and rearrangement within the syntenic regions-have shaped the genomes of each parasite. Contrary to recent reports, our analyses reveal no evidence that these species are descended from an ancestor that contained a photosynthetic endosymbiont.
\end{abstract}

The protozoan pathogens Leishmania major, Trypanosoma cruzi, and Trypanosoma brucei (family Trypanosomatidae, order Kinetoplastida) collectively cause disease and death in millions of humans and countless infections in other mammals, primarily in developing countries in tropical and subtropical regions (1). There are no vaccines for these diseases and only a few drugs, which are inadequate because of toxicity and resistance. Although the three pathogens (referred to here as the "Tritryps") share many general characteristics, including subcellular structures such as the kinetoplast and glycosomes, each is transmitted by a different insect and has its own life-cycle features, different target tissues, and distinct disease pathogenesis in their mammalian host [box 1 in (2) and fig. S1]. They also use different immune evasion strategies: $L$. major alters the function of the macrophages it infects, T. cruzi expresses a complex variety of surface antigens from within the cells it infects, and T. brucei remains extracellular but circumvents the host immune response by the periodic switching of its major surface protein (3).

The availability of the three draft genome sequences (4-6) allows better understanding of the genetic and evolutionary bases of the shared and distinct parasitic modes and lifestyles of these pathogens. In the accompanying Research Articles, the discussion of each species reflects the current state of knowledge for each organism. Thus, the Research Article by Berriman et al. (4) emphasizes metabolism and biochemical pathways of $T$. brucei; the Research Article by Ivens et al. (5) highlights fundamental aspects of molecular biology (transcription, translation, posttranslational modification, and proteolysis) of L. major; and the Research Article by El-Sayed et al. (6) focuses on repeats and retroelements, DNA replication and repair, and signaling pathways of $T$. cruzi. Here, we compare gene content and genome architecture, composition, and organization of protein domains encoded by each genome and offer an analysis of the rates of gene evolution.

Core proteome. The T. brucei, L. major, and $T$. cruzi haploid genomes contain between 25 and 55 megabases $(\mathrm{Mb})$ distributed over 11 to 36 (generally) diploid chromosomes, and encode about 8100,8300 , and 12,000 protein-coding genes, respectively (Table 1). An "all-versusall" basic local alignment search tool (BlastP) comparison of the predicted protein sequences within each of the three genomes was made using a suite of algorithms designed to collapse closely related paralogous genes. In the case of $T$. cruzi, all alleles were included because of the hybrid nature of this genome $(2,6)$. The mutual best BlastP hits between the three collapsed proteomes were grouped as clusters of orthologous genes (COGs). Iteration of this process with manual inspection and reannotation, especially of two-way COGs (i.e., those with members in only two of the Tritryps), resulted in 6158 threeway COGs, which defined the Tritryp core proteome, as well as 1014 two-way COGs (Table 1,

${ }^{1}$ The Institute for Genomic Research, 9712 Medical Center Drive, Rockville, MD 20850, USA. ${ }^{2}$ Department of Microbiology and Tropical Medicine, George Washington University, Washington, DC 20052, USA. ${ }^{3}$ Seattle Biomedical Research Institute, 307 Westlake Avenue North, Seattle, WA 98109-2591, USA. ${ }^{4}$ Department of Pathobiology, University of Washington, Seattle, WA 98195, USA. ${ }^{5}$ Division of Biomedical and Health Informatics, University of Washington, Seattle, WA 98195, USA. ${ }^{6}$ Wellcome Trust Sanger Institute, Wellcome Trust Genome Campus, Hinxton, Cambridgeshire CB10 1SA, UK. ${ }^{7}$ Center for Genomics and Bioinformatics, Karolinska Institutet, Berzelius väg 35, S-171 77 Stockholm, Sweden. ${ }^{8}$ School of Biology, The Devonshire Building, University of Newcastle, Newcastle upon Tyne NE1 7RU, UK. ' ${ }^{9}$ Laboratoire de Génomique Fonctionnelle des Trypanosomatides, UMR-CNRS 5162, Université Victor Segalen Bordeaux II, 33076 Bordeaux cedex, France. ${ }^{10}$ Departamento de Bioquímica e Imunologia, Universidade Federal de Minas Gerais, CEP 31270-901, Belo Horizonte, MD, Brazil. ${ }^{11}$ Medical Research Council Laboratory of Molecular Biology, Hills Road, Cambridge CB2 2QH, UK. ${ }^{12}$ Department of Pathology, University of Cambridge, Tennis Court Road, Cambridge, CB2 1QP, UK. ${ }^{13}$ Department of Biochemistry, University of lowa, 4-403 Bowen Science Building, Newton Road, lowa City, IA 52242, USA.

*These authors contributed equally to this work. $\dagger$ To whom correspondence should be addressed. E-mail: nelsayed@tigr.org (N.M.E.-S.); peter.myler@ sbri.org (P.J.M.); nhall@tigr.org (N.H.)

†Present address: Department of Microbiology, Immunology, and Molecular Genetics, University of California, Los Angeles, CA 90095, USA.

§Present address: The Institute for Genomic Research, 9712 Medical Center Drive, Rockville, MD 20850, USA. 